\title{
A Model of Takeovers of Foreign Banks
}

\author{
Rafael Repullo \\ CEMFI and CEPR
}

Working Paper No. 0015

October 2000

This is a revised version of the Spanish Economic Review lecture delivered at the XXIV Simposio de Análisis Económico, Barcelona, December 1999. The paper was finished during my Houblon-Norman Fellowship at the Bank of England. I want to thank Andrés Almazán, Joan Maria Esteban, Ana Fernandes, Claudio Michelacci, Jorge Padilla, Miguel Pellicer and Javier Suárez for their comments, and Pedro Albarrán for his excellent research assistance. (Email address: repullo@cemfi.es).

CEMFI, Casado del Alisal 5, 28014 Madrid, Spain.

www.cemfi.es 


\begin{abstract}
This paper investigates the determinants of the takeover of a foreign bank by a domestic bank whereby the former becomes a branch of the latter. Each bank is initially supervised by a national agency that cares about closure costs and deposit insurance payouts, and may decide the early closure of the bank on the basis of supervisory information. Under the principle of home country control, the takeover moves responsibility for both the supervision of the foreign bank and the insurance of the foreign deposits to the domestic agency. It is shown that the takeover is more likely to happen if the foreign bank is small (relative to the foreign banking market) and its investments are risky (relative to those of the domestic bank). Moreover, the takeover is in general welfare improving for both countries.
\end{abstract}

Keywords: international banks, takeovers in banking, cross-border bank mergers, bank supervision, bank closure, deposit insurance, home country control.

JEL Classification: G21, G28, G34. 


\section{Introduction}

During the 1990's a very large process of banking consolidation has taken place around the world. ${ }^{1}$ Although most of the action so far has occurred within the domestic markets, there have been a significant number of cross-border mergers. ${ }^{2}$ This process is expected to accelerate in the near future, especially within Europe. As noted by Davis (2000, p.132): "The really new dimension at the outset of the new millennium.... is that of cross-border mergers, which... are now accepted as the logical next step in the European market."

The purpose of this paper is to investigate the determinants of the takeover of a foreign bank by a domestic bank, and its welfare effects for both the domestic and the foreign country. The main result of the paper is that the takeover is more likely to happen if the foreign bank is small (relative to the foreign banking market) and its investments are risky (relative to those of the domestic bank), and if deposit insurance premia are lower in the domestic country. Moreover, the takeover (whenever it happens) is in general welfare improving for both countries.

Three main motives for domestic bank mergers have been discussed in the literature: Economies of scale and scope (including "too big to fail" economies of scale), increases in market power, and risk diversification. ${ }^{3}$ Of these three, the first two are probably not very relevant for cross-border mergers. Economies of scale and scope have been empirically difficult to find for large domestic banks, and the synergies are likely to be smaller in the case of cross-border deals. ${ }^{4}$ On the other hand, the takeover of a foreign bank does not directly increase marker power in either the domestic or the foreign market. So it seems that in order to explain international takeovers in banking one should focus on the risk diversification motive. ${ }^{5}$

\footnotetext{
${ }^{1}$ For example, in the European Union the number of banks fell by $24 \%$ between 1985 and 1997 (European Central Bank, 1999, Table 4.1), while in the US the number of banks fell by $30 \%$ between 1988 and 1997 (Berger et al, 1999, p.138).

${ }^{2}$ Apart from the large number of acquisitions of Latin American banks by Spanish banks, one can cite the 1997 merger between Nordbanken, Sweden's fourth largest bank, and Merita, Finland's biggest bank, and the recently announced merger between HypoVereinsbank (HVB), Germany's second largest bank, with Bank Austria, Austria's biggest bank. See Berger et al (2000) and Dermine (1999) for some data on cross-border bank mergers.

${ }^{3}$ See, for example, Berger et al (1999) and the references therein.

${ }^{4}$ As noted by Berger et al (2000), "...the extensive prior research suggests very few strong conclusions regarding the efficiency effects of cross-border consolidation."

${ }^{5}$ Quoting, again, Berger et al (2000): "The available empirical evidence... suggests that at least
} 
In order to assess the importance of this motive it is worth noting that banks are no ordinary firms. In particular, they have to be licensed by a competent authority, they are subject to strict capital requirements, and some of their liabilities are insured. Moreover, they are supervised by some government agency (which may or may not be the central bank). In this paper we argue that a proper understanding of the risk diversification motive for international takeovers in banking requires taking into account the regulatory and supervisory framework that characterizes the activity of banks.

International banks have two modes of operation in host countries. They can operate via branches (which form a legally dependent part of the home institution) or via subsidiaries (which are separate foreign banks owned by the home institution). According to the Core Principles for Effective Banking Supervision (Basle Committee on Banking Supervision, 1997) the home supervisor should be in charge of the consolidated supervision of their international banks, including overseas branches and subsidiaries. However, the host supervisor is also involved in the case of subsidiaries, since a subsidiary is a registered bank in the host country.

When the international bank owns a subsidiary in a host country, its deposits in this country are insured according to the host country regulation. The situation with regard to deposit insurance is less clear when the international bank opens a branch in a host country. Usually, host authorities require the international bank's deposits in the host country to be covered by the same guarantees as the deposits of domestic banks. For instance, the 1994 European Directive on deposit-guarantee schemes establishes that "each Member State shall ensure that within its territory one or more deposit-guarantee schemes are introduced and officially recognized" (art. 3), and that "deposit-guarantee schemes... shall cover the deposits at branches set up by credit institutions in other Member States" (art. 4).

In this paper we restrict attention to takeovers of a foreign bank by a domestic bank in which the former becomes a branch of the latter whose deposits (like in the European context) are insured by the domestic deposit insurance agency. The analysis is based on a model in which the banks are initially supervised by a national

some types of cross-border consolidation are likely to improve the risk-expected return tradeoff." They also note that the correlations of bank earnings across nations is quite small, and even within the European Union $44 \%$ of them are negative! 
agency that cares about the closure costs and the deposit insurance payouts incurred in case of insolvency. Each agency uses supervisory information (which provides a signal of the future return of the bank's assets) to decide on the early closure of its bank. Under the principle of home country control, the takeover moves responsibility for supervision of the foreign branch to the domestic country.

In deciding whether to close the bank (i.e. withdraw its license to operate) the supervisor compares the current costs of closing the bank with the conditional expectation of the future costs of failure. Assuming that (i) the domestic supervisor does not get any supervisory information on the foreign branch of the domestic bank, (ii) the domestic supervisor does not care about foreign closure costs, and (iii) the returns of domestic and foreign assets are independent, we show that the domestic supervisor will be softer with the international bank than with the original domestic bank. The intuition for this key result is the following. The takeover of the foreign bank by the domestic bank increases the current costs of closing the bank (since foreign depositors have to be compensated) and reduces the conditional expectation of the future costs of failure (since on average the foreign branch is going to be profitable), so the supervisor requires a worse signal to close the bank.

With this result we next analyze the determinants of a takeover of the foreign bank by the domestic bank. In the absence of regulatory constraints, the takeover will take place if the market value of the international bank is greater that the sum of the market values of the domestic and the foreign bank. The higher probability that the international bank will remain open increases the market value of the domestic part of the international bank (relative to the market value of the domestic bank). However, the change in the market value of the foreign part of the international bank (relative to the market value of the foreign bank) may go in the opposite direction. The net effect is more likely to be positive if the foreign bank is a small bank relative to the foreign banking market (so it is not "too big to fail"), and/or its investments are risky relative to those of the domestic bank (so the takeover effectively increases the probability that these risky returns will be realized). Also, it is more likely to be positive if the takeover reduces the deposit insurance premia of the foreign deposits.

Assuming that the domestic (foreign) bank is fully own by domestic (foreign) residents, and that depositors are fully insured, it follows that domestic (foreign) 
social welfare prior to the takeover is simply the sum of the market value of the domestic (foreign) bank and the expected utility of the domestic (foreign) supervisor. Since the owners of the foreign bank are compensated by the owners of the domestic bank (otherwise they would not be willing to sell), it follows that a sufficient condition for the takeover to be welfare improving for the foreign country is that it increases the expected utility of the foreign supervisor. This will obtain whenever the foreign deposit insurance premium is below its fair level (in particular, for large and/or risky foreign banks). As for the domestic country, it is also the case that a sufficient condition for a welfare gain is that it increases the expected utility of the domestic supervisor, which will typically happen as a result of the diversification of the returns of the bank.

It is interesting to note that, in contrast with a large part of the recent theoretical literature on banking, moral hazard issues (in particular risk-shifting incentives) play no role in our model. To the extent that consolidation requires an increase the market value of the combined entity, these incentives are likely to be ameliorated, ${ }^{6}$ so taking them into account may actually increase the likelihood and the welfare gains of international takeovers.

The remainder of this paper is organized as follows. Section 2 presents the model of the domestic and the foreign bank and characterizes the closure policies of domestic and the foreign supervisor. Section 3 assumes that the domestic bank buys the foreign bank, and characterizes the closure policy of the domestic supervisor with regard to the international bank. Section 4 discusses the effects of the takeover on the probability of bank failures. Section 5 analyzes the determinants of international takeovers, that is under what conditions the market value of the international bank is greater than the sum of the market values of the domestic and the foreign bank. Section 6 looks at the welfare effects of the takeover for the domestic and the foreign country. Finally, Section 7 offers some concluding remarks.

\footnotetext{
${ }^{6}$ On the connection between franchise values and risk-shifting incentives see Hellmann et al (2000).
} 


\section{The Model}

\subsection{The Domestic Bank}

Consider a discrete time, infinite horizon model of a bank that receives from a government agency a license to operate at an initial date $t=0$. The agency supervises the bank and has the authority to withdraw the license and close the bank at any date. This will happen when either the bank is revealed to be insolvent, that is when the value of its assets is smaller than the value of its deposits, or when the agency observes some negative information about the future return of the bank's assets.

At any date $t=0,1,2, \ldots$ in which it remains open, the bank raises 1 unit of deposits. These funds are invested in an asset that yields an iid random return $\widetilde{R}$ at date $t+1$. It is assumed that

$$
\widetilde{R}=\left\{\begin{array}{c}
R, \quad \text { with probability } p \\
0, \quad \text { with probability } 1-p
\end{array}\right.
$$

where $E(\widetilde{R})=p R>1$. The asset can also be liquidated at the intermediate date $t+\alpha$, where $\alpha \in(0,1)$. The liquidation value of the asset is $L \in(0,1)$.

Deposits pay an interest rate that is normalized to zero, and are fully insured by a deposit insurance corporation. The corporation charges a flat-rate deposit insurance premium $\phi$. This premium is paid at date $t$ by the owners of the bank. To simplify the presentation, we assume that, apart from this payment, the bank owners do not contribute any additional funds, so the bank's investment in the risky asset is equal to the amount of deposits.

After the investment is made, the supervisory agency observes at date $t+\alpha$ a nonverifiable signal $s \in[0,1]$ that contains information about $\widetilde{R}$. In particular, it is assumed that

$$
\widetilde{R} \mid s=\left\{\begin{array}{l}
R, \quad \text { with probability } s \\
0, \quad \text { with probability } 1-s
\end{array}\right.
$$

From the point of view of date $t$, the supervisory information is a random variable $\widetilde{s}$ with cumulative distribution function $F(s)$ and density function $f(s)$. Notice that for (2) to be consistent with (1) we require $E(\widetilde{s})=\int_{0}^{1} s d F(s)=p$.

Following the observation of the signal $s$, the supervisor decides whether to close 
the bank or leave it open. ${ }^{7}$ We assume that the supervisor is risk neutral and that her objective function coincides with that of the deposit insurance corporation, namely to minimize expected total costs. ${ }^{8}$ These costs comprise the compensation paid to depositors as well as a closure cost $c$ that captures the negative externalities associated with a bank failure (in particular, via potential contagion to other banks).

According to this, if the bank is closed at date $t+\alpha$ the supervisor incurs a total cost $1-L+c$, where $1-L$ is the net payment to depositors (recall that the liquidation value of the asset is $L$ ), and $c$ is the closure cost. On the other hand, if the bank stays open it will fail at date $t+1$ with probability $1-s$, in which case the supervisor incurs a total cost $1+c .{ }^{9}$ Hence the supervisor's policy is to close the bank if

$$
1-L+c<(1-s)(1+c)
$$

Solving for $s$ in this expression gives the following result.

Proposition 1 There exists a critical value

$$
\widehat{s}=\frac{L}{1+c} .
$$

such that the supervisor closes the bank at date $t+\alpha$ if $s<\widehat{s}$.

It should be noticed that the critical value $\widehat{s}$ is increasing in $L$ and decreasing in c. This means that the supervisor is softer with banks which have lower liquidation values, and with banks whose failure entails large closure costs. Since one would expect large banks to be characterized by large $c$ 's, ${ }^{10}$ this implies a "too big to fail" result: large banks would be treated by the supervisor with more leniency than smaller banks.

The probability that the bank will be closed by the supervisor at date $t+\alpha$ is given by

$$
z_{\alpha}=\operatorname{Pr}(s<\widehat{s})=F(\widehat{s}) .
$$

\footnotetext{
${ }^{7}$ Notice that since the signal $s$ is nonverifiable, the closure decision cannot be specified ex ante.

${ }^{8}$ This corresponds to what Mailath and Mester (1994) called a "cost-minimizing regulator." A similar assumption is made in Repullo (2000).

${ }^{9}$ Notice that we are implicitly assuming that the supervisor is "myopic" in that she does not take into account the future costs associated with keeping the bank open. We will come back to this issue below.

${ }^{10}$ Recall that the volume of deposits is 1 , so this is equivalent to saying that closure costs increase more than proportionately with the size of the bank's balance sheet.
} 
Similarly, the probability that the bank will fail at date $t+1$ is

$$
z_{1}=\operatorname{Pr}(s \geq \widehat{s} \text { and } \widetilde{R}=0)=\operatorname{Pr}(\widetilde{R}=0 \mid s \geq \widehat{s}) \operatorname{Pr}(s \geq \widehat{s})=\int_{\widehat{s}}^{1}(1-s) d F(s) .
$$

From (4) and (5) it follows that the probability that the bank will be closed at date $t+\alpha$ or fail at date $t+1$ is

$$
z_{\alpha}+z_{1}=1-\int_{\widehat{s}}^{1} s d F(s)
$$

Using these expressions we can compute the effects of an increase in the critical value $\widehat{s}$ that characterizes the closure policy of the supervisor:

$$
\frac{d z_{\alpha}}{d \widehat{s}}=f(\widehat{s})>0 ; \quad \frac{d z_{1}}{d \widehat{s}}=-(1-\widehat{s}) f(\widehat{s})<0 ; \quad \frac{d\left(z_{\alpha}+z_{1}\right)}{d \widehat{s}}=\widehat{s} f(\widehat{s})>0 .
$$

Hence a tougher closure policy increases the probability that the bank will be closed at date $t+\alpha$, and decreases the probability that the bank will fail at date $t+1$. Moreover, the first effect is larger than the second, so the probability $1-z_{\alpha}-z_{1}$ that the bank owners will receive the return $R-1$ at date $t+1$ is decreasing in $\widehat{s}$.

Under risk neutrality, and assuming a zero discount rate, the market value of the bank at any date $t$ in which it remains open, denoted by $V$, satisfies the equation

$$
V=-\phi+\left(1-z_{\alpha}-z_{1}\right)(R-1+V)
$$

The first term in the right hand side is the deposit insurance premium paid by the bank owners at date $t$, and the second term is their expected return at date $t+1$ : with probability $z_{\alpha}+z_{1}$ they will get 0 and lose the bank's license, and with probability $1-z_{\alpha}-z_{1}$ they will get $R-1$ plus the value $V$ of the bank at date $t+1$. Solving for $V$ in this equation then gives

$$
V=\frac{\left(1-z_{\alpha}-z_{1}\right)(R-1)-\phi}{z_{\alpha}+z_{1}}
$$

Notice that $V$ is the value of the bank's charter (the net present value of the rents that the bank owners will obtained as long as the bank stays open), which in this model is endogenous. ${ }^{11}$

\footnotetext{
${ }^{11}$ This approach to endogenizing charter (or franchise) values is taken from Suarez (1994). On the role of charter values in banking see also Keeley (1990) and Hellmann et al (2000).
} 
Similarly, the expected utility of the supervisor at any date $t$ in which the bank remains open, denoted by $U$, satisfies the equation

$$
U=\phi-z_{\alpha}(1-L+c)-z_{1}(1+c)+\left(1-z_{\alpha}-z_{1}\right) U
$$

The first term in the right hand side is the deposit insurance premium paid by the bank owners at date $t$, the second term is the expected total cost incurred by the supervisor if she closes the bank at date $t+\alpha$, the third term is her expected total cost if the bank fails at date $t+1$, and the last term takes into account that fact that with probability $1-z_{\alpha}-z_{1}$ the bank will stay open and the supervisor will get the expected utility $U$. Solving for $U$ in this equation then gives

$$
U=\frac{\phi-z_{\alpha}(1-L+c)-z_{1}(1+c)}{z_{\alpha}+z_{1}}=\frac{\phi-z_{\alpha}(1-L)-z_{1}}{z_{\alpha}+z_{1}}-c .
$$

The deposit insurance premium $\phi$ is said to be "fair" if it is equal to the expected compensation paid to depositors, that is if

$$
\phi=z_{\alpha}(1-L)+z_{1}
$$

Notice that, by (7), in the case of fair premia the expected utility of the supervisor is simply $-c$.

However, in the real world deposit insurance premia are not typically fair. Rather, they are set with reference to the average riskiness of the banks, so riskier banks will in fact be subsidized by safer banks. This is in fact the assumption that will be made below.

So far we have implicitly assumed that the supervisor is "myopic" in that she does not take into account the future costs associated with keeping the bank open. If the supervisor were non-myopic, her expected utility would be

$$
U^{\prime}=\phi-E\left[\min \left\{1-L+c,(1-s)(1+c)-s U^{\prime}\right\}\right]
$$

From here it follows that the critical value below which the supervisor closes the bank would become

$$
\widehat{s}^{\prime}=\frac{L}{1+c+U^{\prime}} .
$$

Let $z_{\alpha}^{\prime}$ and $z_{1}^{\prime}$ denote the corresponding probabilities that the bank will be closed by the supervisor at date $t+\alpha$ and fail at date $t+1$, respectively. Then it is immediate 
to show that $U^{\prime}$ satisfies

$$
U^{\prime}=\frac{\phi-z_{\alpha}^{\prime}(1-L)-z_{1}^{\prime}}{z_{\alpha}^{\prime}+z_{1}^{\prime}}-c
$$

Hence in the case of fair premia we would have $U^{\prime}=-c$ and $\widehat{s}^{\prime}=L$. On the other hand, if the deposit insurance premium were set to cover also the closure costs, so $U^{\prime}=0$, we would have $\widehat{s}=\widehat{s}$. At any rate, in the rest of the paper we will restrict attention to the case of a myopic supervisor.

Assuming that the domestic bank is fully own by domestic residents, social welfare in the domestic country, denoted by $W$, is simply the sum of the expected utilities of the bank owners and the supervisor, ${ }^{12}$ that is

$$
W=V+U
$$

We will use this expression in Section 6 in order to assess the welfare effects for the domestic country of a takeover of a foreign bank by the domestic bank.

\subsection{The Foreign Bank}

Consider now a foreign bank that at any date $t=0,1,2, \ldots$ in which it remains open raises an amount $\lambda$ of deposits. We assume that $\lambda<1$, so the foreign bank is smaller than the domestic bank. These funds are invested in a foreign asset that yields an iid random return $\lambda \widetilde{R}^{*}$ at date $t+1$. As before, it is assumed that

$$
\widetilde{R}^{*}=\left\{\begin{array}{c}
R^{*}, \quad \text { with probability } p^{*} \\
0, \quad \text { with probability } 1-p^{*}
\end{array}\right.
$$

where $E\left(\widetilde{R}^{*}\right)=p^{*} R^{*}>1$. Moreover, we assume that the return $\widetilde{R}^{*}$ of the foreign asset is independent of the return $\widetilde{R}$ of the asset of the domestic bank. ${ }^{13}$ The foreign asset can be liquidated at date $t+\alpha$, and its liquidation value is $\lambda L^{*} \in(0, \lambda)$.

Foreign deposits pay an interest rate that is normalized to zero, and are fully insured by a foreign deposit insurance corporation. The corporation charges a flatrate deposit insurance premium $\phi^{*}$ per unit of deposits. As in the case of the domestic

\footnotetext{
${ }^{12}$ Recall that the depositors are fully insured, so they always get 0 in net terms.

${ }^{13}$ This seems a reasonable assumption in the light of the evidence in footnote 5.
} 
bank, we assume that the premium $\lambda \phi^{*}$ is paid at date $t$ by the owners of the foreign bank.

There is a foreign supervisor that observes at date $t+\alpha$ a nonverifiable signal $s^{*} \in[0,1]$ that contains information about $\widetilde{R}^{*}$. In particular, it is assumed that

$$
\widetilde{R}^{*} \mid s^{*}=\left\{\begin{array}{c}
R^{*}, \quad \text { with probability } s^{*} \\
0, \quad \text { with probability } 1-s^{*}
\end{array}\right.
$$

From the point of view of date $t$, the supervisory information is a random variable $\widetilde{s}^{*}$ with cumulative distribution function $F^{*}\left(s^{*}\right)$ and density function $f^{*}\left(s^{*}\right) .{ }^{14}$

After observing the signal $s^{*}$, the foreign supervisor decides whether to close the bank or leave it open. Assuming, as before, that the supervisor is risk neutral and that her objective function coincides with that of the deposit insurance corporation, we could follow the same steps as in the previous section to prove the analogue of Proposition 1, which defines a critical value

$$
\widehat{s}^{*}=\frac{L^{*}}{1+c^{*}}
$$

below which the foreign supervisor closes the bank.

As in the case of the domestic bank, we can compute the probability that the foreign bank will be closed at date $t+\alpha$

$$
z_{\alpha}^{*}=\operatorname{Pr}\left(s^{*}<\widehat{s}^{*}\right)=F^{*}\left(\widehat{s}^{*}\right)
$$

and the probability that the bank will fail at date $t+1$

$$
z_{1}^{*}=\operatorname{Pr}\left(s^{*} \geq \widehat{s}^{*} \text { and } \widetilde{R}^{*}=0\right)=\int_{\widehat{s}^{*}}^{1}\left(1-s^{*}\right) d F^{*}\left(s^{*}\right) .
$$

The market value of the foreign bank at any date $t$ in which it remains open, denoted by $V^{*}$, is then given by

$$
V^{*}=\frac{\lambda\left[\left(1-z_{\alpha}^{*}-z_{1}^{*}\right)\left(R^{*}-1\right)-\phi^{*}\right]}{z_{\alpha}^{*}+z_{1}^{*}},
$$

Similarly, the expected utility of the foreign supervisor, denoted by $U^{*}$, is

$$
U^{*}=\frac{\lambda\left[\phi^{*}-z_{\alpha}^{*}\left(1-L^{*}\right)-z_{1}^{*}\right]}{z_{\alpha}^{*}+z_{1}^{*}}-\lambda c^{*} .
$$

\footnotetext{
${ }^{14}$ Notice that since $\widetilde{R}^{*}$ and $\widetilde{R}$ are independent, it must be the case that $\widetilde{s}^{*}$ and $\widetilde{s}$ are also independent.
} 
Assuming that the foreign bank is fully own by foreign residents, foreign social welfare, denoted by $W^{*}$, is given by

$$
W^{*}=V^{*}+U^{*}
$$

This expression will be used in Section 6 to assess the welfare effects for the foreign country of a takeover of the foreign bank by the domestic bank.

\section{The International Bank}

In this section we suppose that the domestic bank buys the foreign bank, which now becomes a branch (not a subsidiary) of the domestic bank. The resulting international bank raises 1 unit of deposits in the domestic market and $\lambda$ units in the foreign market at each date $t$ in which it remains open. These funds are invested in a portfolio of domestic and foreign assets that yields a random return $\widetilde{R}+\lambda \widetilde{R}^{*}$ at date $t+1$. If the bank is liquidated at date $t+\alpha$, the liquidation value of the bank's portfolio is $L+\lambda L^{*}$.

By (1) and (9) the final return of the international bank at date $t+1$ can take four values: $R+\lambda R^{*}, R, \lambda R^{*}$, and 0 . Clearly we have $R+\lambda R^{*}>R>0$ and $R+\lambda R^{*}>$ $\lambda R^{*}>0$, but in principle we could have $R \lessgtr \lambda R^{*}$. In what follows we assume that $\lambda$ is small enough so as to ensure that

$$
R \geq 1+\lambda>\lambda R^{*}
$$

This means that the international bank fails at date $t+1$ if and only if its investments in the domestic country fail.

Under the assumption of home country control, the domestic authorities supervise the international bank and insure all its deposits (including the foreign deposits). Furthermore, we assume that the domestic deposit insurance corporation charges the international bank the same premium $\phi$ per unit of deposits than it charged the domestic bank. The rationale for this assumption is that the takeover of the foreign bank by the domestic bank may not significantly affect the average riskiness of the banks based in the domestic country. As before, the premium $(1+\lambda) \phi$ is paid at date $t$ by the owners of the international bank.

The domestic supervisor observes at date $t+\alpha$ the signal $s$ on $\widetilde{R}$. However, because of geographical distance, lack of familiarity with the business, accounting, and legal 
practices in the foreign country, etc. this supervisor is not able to observe the signal $s^{*}$ on $\widetilde{R}^{*}{ }^{15}$ We also assume that when deciding whether to close the international bank, the domestic supervisor only takes into account the closure cost $c$ incurred in the domestic country. To be sure, the closure cost $c^{*}$ is still incurred in the foreign country, but the domestic supervisor ignores it when deciding what to do with the international bank.

We are now ready to characterize the closure policy of the domestic supervisor with regard to the international bank. Consider her decision problem after she has observed the signal $s$. If the international bank is closed at date $t+\alpha$ she incurs a total cost $1-L+\lambda\left(1-L^{*}\right)+c$, where $1-L$ is the net payment to domestic depositors, $\lambda\left(1-L^{*}\right)$ is the net payment to foreign depositors, and $c$ is the domestic closure cost. On the other hand, if the bank stays open it will fail at date $t+1$ when $\widetilde{R}=0$, which happens with probability $1-s$, in which case the domestic supervisor incurs a total cost $1+\lambda+c$, when $\widetilde{R}^{*}=0$, and $1+\lambda\left(1-R^{*}\right)+c$, when $\widetilde{R}^{*}=R^{*}$. Since the supervisor does not observe the signal $s^{*}$, and by independence we have $\operatorname{Pr}\left(\widetilde{R}^{*}=R^{*} \mid \widetilde{R}=0\right)=\operatorname{Pr}\left(\widetilde{R}^{*}=R^{*}\right)=p^{*}$, in expected terms this cost is equal to $1+\lambda\left(1-p^{*} R^{*}\right)+c$. Hence the policy of the domestic supervisor is to close the international bank if

$$
1-L+\lambda\left(1-L^{*}\right)+c<(1-s)\left[1+\lambda\left(1-p^{*} R^{*}\right)+c\right]
$$

which leads to the following result.

Proposition 2 There exists a critical value

$$
\bar{s}=\frac{L-\lambda\left(p^{*} R^{*}-L^{*}\right)}{1+\lambda\left(1-p^{*} R^{*}\right)+c}
$$

such that the domestic supervisor closes the international bank at date $t+\alpha$ if $s<\bar{s}$. Moreover $\bar{s}<\widehat{s}$.

Proof By (17) we have $1+\lambda>\lambda R^{*}$, which implies $1+\lambda\left(1-p^{*} R^{*}\right)+c>0$. Hence solving for $s$ in (18) proves the first part of the proposition. Next by (19) and (3) it

\footnotetext{
${ }^{15} \mathrm{~A}$ less restrictive assumption would be that the domestic supervisor observes a signal on $\widetilde{R}^{*}$ that is noisier than the signal $s^{*}$ received by the foreign supervisor prior to the takeover. This would considerably complicate the analysis, but the qualitative results would be essentially unchanged.
} 
is immediate to check that $\bar{s}<\widehat{s}$ if and only if

$$
\left(p^{*} R^{*}-L^{*}\right)(1+c)>\left(p^{*} R^{*}-1\right) L \text {. }
$$

But $L^{*}<1$ and $(1+c)>L$ imply

$$
\left(p^{*} R^{*}-L^{*}\right)(1+c)>\left(p^{*} R^{*}-1\right)(1+c)>\left(p^{*} R^{*}-1\right) L
$$

so we conclude that $\bar{s}<\widehat{s}$.

The fact that $\bar{s}<\widehat{s}$ implies that the domestic supervisor is softer with the international bank than with the original domestic bank. The reason for this key result is the following. The takeover of the foreign bank by the domestic bank increases the costs of closing the bank at date $t+\alpha$ by $\lambda\left(1-L^{*}\right)$, and because of the diversification of returns it reduces the expected costs of failure at date $t+1$ by $(1-s) \lambda\left(p^{*} R^{*}-1\right),{ }^{16}$ so now the supervisor is more inclined to keep the bank open. ${ }^{17}$

The probability that the international bank will be closed at date $t+\alpha$ is given by

$$
\bar{z}_{\alpha}=\operatorname{Pr}(s<\bar{s})=F(\bar{s}) .
$$

Similarly, the probability that the international bank will fail at date $t+1$ is

$$
\bar{z}_{1}=\operatorname{Pr}(s \geq \bar{s} \text { and } \widetilde{R}=0)=\int_{\bar{s}}^{1}(1-s) d F(s) .
$$

Hence the probability that the international bank will be closed at date $t+\alpha$ or fail at date $t+1$ is

$$
\bar{z}_{\alpha}+\bar{z}_{1}=1-\int_{\bar{s}}^{1} s d F(s) .
$$

To compute the market value of the international bank at any date $t$ in which it remains open, denoted by $\bar{V}$, observe that the bank owners pay the deposit insurance premium $(1+\lambda) \phi$ at date $t$, and will receive a positive payoff plus the value $\bar{V}$ of the bank at date $t+1$ when $s \geq \bar{s}$ and $\widetilde{R}=R$. This payoff will be $R-(1+\lambda)$, when $\widetilde{R}=0$, and $R+\lambda R^{*}-(1+\lambda)$, when $\widetilde{R}^{*}=R^{*}$. Since $\operatorname{Pr}(s \geq \bar{s}$ and $\widetilde{R}=R)=1-\bar{z}_{\alpha}-\bar{z}_{1}$

\footnotetext{
${ }^{16}$ Recall that we are assuming $p^{*} R^{*}>1$.

${ }^{17}$ Moreover, it is clear from (19) that as $\lambda$ goes to zero, the effect of the takeover on the behavior of the domestic supervisor becomes smaller and smaller, and in the limit we have $\lim _{\lambda \rightarrow 0} \bar{s}=\widehat{s}$.
} 
and by independence $\operatorname{Pr}\left(\widetilde{R}^{*}=R^{*} \mid \widetilde{R}=R\right)=\operatorname{Pr}\left(\widetilde{R}^{*}=R^{*}\right)=p^{*}$, we conclude that the market value of the international bank satisfies the equation

$$
\bar{V}=-(1+\lambda) \phi+\left(1-\bar{z}_{\alpha}-\bar{z}_{1}\right)\left[R+\lambda p^{*} R^{*}-(1+\lambda)+\bar{V}\right]
$$

which gives

$$
\bar{V}=\frac{\left(1-\bar{z}_{\alpha}-\bar{z}_{1}\right)\left[R+\lambda p^{*} R^{*}-(1+\lambda)\right]-(1+\lambda) \phi}{\bar{z}_{\alpha}+\bar{z}_{1}} .
$$

To sum up, in this section we have characterized the behavior of the (domestic) supervisor that is responsible for the international bank resulting from the takeover of the foreign bank by the domestic bank. In particular, we have shown that this supervisor is softer with the international bank than with the original domestic bank. Moreover, we have computed the market value of the international bank. These results will be used to discuss the determinants and the welfare effects of international takeovers in banking. As a preliminary step, we first find out its effects on the probability of bank failures.

\section{The Effects on the Probability of Bank Failures}

In this section we compare the probabilities that the international bank will be closed at date $t+\alpha$ or fail at date $t+1$ with the corresponding probabilities for the domestic and the foreign bank prior to the merger.

In Section 3 we showed that the critical value $\bar{s}$ below which the domestic supervisor closes the international bank at date $t+\alpha$ is smaller that the critical value $\widehat{s}$ below which it closed the domestic bank. Hence by (20) and (4) this implies

$$
\bar{z}_{\alpha}=F(\bar{s})<F(\widehat{s})=z_{\alpha},
$$

so the probability that the international bank will be closed at date $t+\alpha$ is smaller than the corresponding probability for the domestic bank. On the other hand, by (21) and (5), $\bar{s}<\widehat{s}$ implies

$$
\bar{z}_{1}=\int_{\bar{s}}^{1}(1-s) d F(s)>\int_{\widehat{s}}^{1}(1-s) d F(s)=z_{1},
$$

so the probability that the international bank will fail at date $t+1$ is greater than the corresponding probability for the domestic bank. However since

$$
\bar{z}_{\alpha}+\bar{z}_{1}=1-\int_{\bar{s}}^{1} s d F(s)<1-\int_{\widehat{s}}^{1} s d F(s)=z_{\alpha}+z_{1},
$$


the first effect is larger than the second. In particular, this means that the probability that the owners of the international bank will receive a positive payoff and keep the bank open at date $t+1$ is larger than the corresponding probability for the domestic bank.

Next we compare the closure policy of the domestic supervisor with regard to the international bank with the closure policy of the foreign supervisor prior to the merger. The probability of closure of the international bank at date $t+\alpha$ is smaller than the corresponding probability for the foreign bank if

$$
\bar{z}_{\alpha}=F(\bar{s})<F^{*}\left(\widehat{s}^{*}\right)=z_{\alpha}^{*}
$$

Since $\bar{s}<\widehat{s}$, this condition will be satisfied if

$$
\widehat{s}=\frac{L}{1+c}=\frac{L^{*}}{1+c^{*}}=\widehat{s}^{*}
$$

and $F=F^{*}$. On the other hand, if either $\widehat{s}^{*}<\widehat{s}$, or if $F$ is dominated by $F^{*}$ in the sense of first order stochastic dominance, $\bar{z}_{0}$ may be larger than $z_{0}^{*}$. The first case happens when $c^{*}$ is relatively large, that is when the foreign bank is a large bank in the foreign banking market, so the foreign supervisor will be less inclined to close it at date $t+\alpha$. On the other hand, in the second case we have $E(\widetilde{s})=p<p^{*}=E\left(\widetilde{s}^{*}\right)$, so the investments of the foreign bank are safer than those of the domestic bank. Moreover, these two effects are more likely to make $\bar{z}_{\alpha}>z_{\alpha}^{*}$ when $\bar{s}$ is close to $\widehat{s}$, in particular when $\lambda$ (the relative size of the foreign bank) is small. Hence we conclude that $\bar{z}_{\alpha}$ will in general be smaller than $z_{\alpha}^{*}$ unless the foreign bank is a large bank in the foreign banking market that invests in relatively safe assets, and that is small relative to the domestic bank.

Similarly, we can conclude that

$$
\bar{z}_{1}=\int_{\bar{s}}^{1}(1-s) d F(s)>\int_{\widehat{s}^{*}}^{1}\left(1-s^{*}\right) d F^{*}\left(s^{*}\right)=z_{1}^{*},
$$

and

$$
\bar{z}_{\alpha}+\bar{z}_{1}=1-\int_{\bar{s}}^{1} s d F(s)<1-\int_{\widehat{s}^{*}}^{1} s^{*} d F^{*}\left(s^{*}\right)=z_{\alpha}^{*}+z_{1}^{*},
$$

unless the foreign bank is large (relative to the foreign banking market) and safe (relative to the domestic bank), and the domestic bank is large (relative to the foreign bank). 
To illustrate these results we use the following parameterization. Let

$$
F(s)=s^{\frac{p}{1-p}}
$$

and similarly for $F^{*}\left(s^{*}\right)$. Observe that $F(0)=0$ and $F(1)=1$. Moreover one can easily check that $E(\widetilde{s})=p$. We take $p=.90$ and $c=.10$, and compute $\bar{z}_{\alpha}+\bar{z}_{1}-\left(z_{\alpha}^{*}+z_{1}^{*}\right)$, that is the change in the probability of failure of the foreign bank after the takeover, for $p^{*}=.85, .90$, and $.95, c^{*}=0, .10$, and .40 , and $\lambda=.10$, and $.25 .{ }^{18}$ Table 1 shows the results.

TABLE 1: Change in the probability of failure of the foreign bank

$$
\left(\bar{z}_{\alpha}+\bar{z}_{1}-\left(z_{\alpha}^{*}+z_{1}^{*}\right)\right)
$$

$$
\text { Panel A: } \lambda=.10
$$

\begin{tabular}{|c|c|c|c|}
\cline { 2 - 4 } \multicolumn{1}{c|}{} & $p^{*}=.85$ & $p^{*}=.90$ & $p^{*}=.95$ \\
\hline$c^{*}=0$ & -.163 & -.039 & +.058 \\
\hline$c^{*}=.10$ & -.104 & -.008 & +.061 \\
\hline$c^{*}=.40$ & -.051 & +.010 & +.061 \\
\hline
\end{tabular}

Panel B: $\lambda=.25$

\begin{tabular}{|c|c|c|c|}
\cline { 2 - 4 } \multicolumn{1}{c|}{} & $p^{*}=.85$ & $p^{*}=.90$ & $p^{*}=.95$ \\
\hline$c^{*}=0$ & -.169 & -.046 & +.051 \\
\hline$c^{*}=.10$ & -.111 & -.015 & +.054 \\
\hline$c^{*}=.40$ & -.058 & +.003 & +.054 \\
\hline
\end{tabular}

All the numbers in the first column of both panels are negative, which means that if the foreign bank is riskier than the domestic bank $\left(p^{*}=.85<.90=p\right)$, the probability that the bank is closed at date $t+\alpha$ or fails at date $t+1$ goes down. Conversely, all the numbers in the third column of both panels are positive. It can also be seen how an increase in the foreign closure cost, $c^{*}$, which proxies the size of the foreign bank in the foreign banking market, reduces $z_{\alpha}^{*}+z_{1}^{*}$ and hence increases the numbers in each column. Finally, comparing the numbers in Panel A with those

\footnotetext{
${ }^{18}$ The other parameter values are $L=L^{*}=.75$ and $R=R^{*}=1.5$. Notice that for the chosen parameter values the assumptions $p R>1, p^{*} R^{*}>1$, and $R \geq 1+\lambda>\lambda R^{*}$ are satisfied.
} 
in Panel B we conclude that an increase in the relative size of the foreign bank (an increase in $\lambda$ ) reduces the difference $\bar{z}_{\alpha}+\bar{z}_{1}-\left(z_{\alpha}^{*}+z_{1}^{*}\right)$.

It should also be noticed that for $p^{*}=.90$ and $c^{*}=.10$ we have $z_{\alpha}^{*}+z_{1}^{*}=z_{\alpha}+z_{1}$ (since $p=.90$ and $c=0.10$ ). Hence the takeover of the foreign bank reduces the probability of failure of the domestic bank by $.8 \%$ when $\lambda=.10$ and by $1.5 \%$ when $\lambda=.25$.

Since by (6), (14), and (22) the market values $V, V^{*}$, and $\bar{V}$ of the domestic, the foreign, and the international bank are decreasing in $z_{\alpha}+z_{1}, z_{\alpha}^{*}+z_{1}^{*}$, and $\bar{z}_{\alpha}+\bar{z}_{1}$, respectively, the results in this section help to identify the key factors in the analysis of international takeovers in banking that follows.

\section{The Determinants of International Takeovers}

In this section we analyze under what conditions the market value of the international bank, $\bar{V}$, is greater that the sum of the market values of the domestic and the foreign bank, $V+V^{*}$. This is a necessary (and, in the absence of regulatory constraints, also a sufficient) condition for the takeover of the foreign bank by the domestic bank.

Using (6), (14), and (22), and rearranging gives

$$
\begin{aligned}
\bar{V}-\left(V+V^{*}\right)= & (R-1-\phi)\left(\frac{1}{\bar{z}_{\alpha}+\bar{z}_{1}}-\frac{1}{z_{\alpha}+z_{1}}\right) \\
& +\lambda\left(R^{*}-1-\phi\right)\left(\frac{1}{\bar{z}_{\alpha}+\bar{z}_{1}}-\frac{1}{z_{\alpha}^{*}+z_{1}^{*}}\right) \\
& -\lambda\left(1-p^{*}\right) R^{*}\left(\frac{1}{\bar{z}_{\alpha}+\bar{z}_{1}}-1\right)-\lambda\left(\phi-\phi^{*}\right) \frac{1}{z_{\alpha}^{*}+z_{1}^{*}} .
\end{aligned}
$$

By (25) we have $\bar{z}_{\alpha}+\bar{z}_{1}<z_{\alpha}+z_{1}$, so the first term on the right hand side is positive. The second term is also positive as long as $\bar{z}_{\alpha}+\bar{z}_{1}<z_{\alpha}^{*}+z_{1}^{*}$, which by our discussion in the previous section requires that the foreign bank be not too large (relative to the foreign banking market) or too safe (relative to the domestic bank), and that the domestic bank be not too large (relative to the foreign bank). The third term is always negative. Finally, the fourth term is negative (positive) if the deposit insurance premium in the domestic country, $\phi$, is greater (smaller) than the premium in the foreign country, $\phi^{*}$. 
Three analytical results can be immediately derived from this expression. First, since the domestic supervisor does not care about the closure cost incurred in the foreign country, $c^{*}$ only appears in $z_{\alpha}^{*}+z_{1}^{*}$, so we can compute

$$
\frac{\partial\left[\bar{V}-\left(V+V^{*}\right)\right]}{\partial c^{*}}=\lambda\left(R^{*}-1-\phi^{*}\right) \frac{1}{\left(z_{\alpha}^{*}+z_{1}^{*}\right)^{2}} \frac{d\left(z_{\alpha}^{*}+z_{1}^{*}\right)}{d \widehat{s}^{*}} \frac{\partial \widehat{s}^{*}}{\partial c^{*}} .
$$

But we have seen in Section 2 that

$$
\frac{d\left(z_{\alpha}^{*}+z_{1}^{*}\right)}{d \widehat{s}^{*}}=\widehat{s}^{*} f^{*}\left(\widehat{s}^{*}\right)>0
$$

and by (11) we have

$$
\frac{\partial \widehat{s}^{*}}{\partial c^{*}}=-\frac{L^{*}}{\left(1+c^{*}\right)^{2}}<0,
$$

so we conclude that a higher closure cost reduces the difference $\bar{V}-\left(V+V^{*}\right)$, and hence makes the takeover less likely.

Second, since the deposit insurance premium in the foreign country, $\phi^{*}$, only enters in the fourth term of (26) we can also compute

$$
\frac{\partial\left[\bar{V}-\left(V+V^{*}\right)\right]}{\partial \phi^{*}}=\frac{\lambda}{z_{\alpha}^{*}+z_{1}^{*}}>0 .
$$

Hence a higher foreign deposit insurance premium increases the likelihood of a takeover of the foreign bank by the domestic bank.

Finally, we can easily compute

$$
\frac{\partial\left[\bar{V}-\left(V+V^{*}\right)\right]}{\partial \phi}=-\left(\frac{1}{\bar{z}_{\alpha}+\bar{z}_{1}}-\frac{1}{z_{\alpha}+z_{1}}\right)-\frac{\lambda}{\bar{z}_{\alpha}+\bar{z}_{1}}<0,
$$

so a higher domestic deposit insurance premium makes the takeover less likely. These results are formally stated in the following proposition.

Proposition 3 The takeover of the foreign bank by the domestic bank is more likely to happen the lower the foreign closure cost, $c^{*}$, and the domestic deposit insurance premium, $\phi$, and the higher the foreign deposit insurance premium, $\phi^{*}$.

According to this result, target banks are expected to be small banks located in countries with relatively high deposit insurance premia.

Analytical results for other key parameters of the model, in particular the probabilities $p$ and $p^{*}$ of success of the investments of the domestic and the foreign bank 
and the relative size $\lambda$ of the foreign bank, are more difficult to obtain. For this reason, we will present some numerical results using the parameterization introduced in the previous section. Table 2 shows the values of $\bar{V}-\left(V+V^{*}\right)$ for $p=.90$ and $c=.10$, and for $p^{*}=.85, .90$, and $.95, c^{*}=0, .10$, and .40 , and $\lambda=.10$, and .25 . The numbers are computed assuming that the deposit insurance premium $\phi$ is fair for the domestic bank prior to the takeover, and that $\phi^{*}=\phi$ (so it is also fair for the foreign bank when $p^{*}=.90$ and $\left.c^{*}=.10\right)$.

TABLE 2: Difference between the market value of the international bank and the sum of the market values of the domestic and the foreign bank

$$
\left(\bar{V}-\left(V+V^{*}\right)\right)
$$

Panel A: $\lambda=.10$

\begin{tabular}{|c|c|c|c|}
\cline { 2 - 4 } \multicolumn{1}{c|}{} & $p^{*}=.85$ & $p^{*}=.90$ & $p^{*}=.95$ \\
\hline$c^{*}=0$ & +.257 & +.211 & -.208 \\
\hline$c^{*}=.10$ & +.217 & +.141 & -.247 \\
\hline$c^{*}=.40$ & +.157 & +.082 & -.254 \\
\hline
\end{tabular}

Panel B: $\lambda=.25$

\begin{tabular}{|c|c|c|c|}
\cline { 2 - 4 } \multicolumn{1}{c|}{} & $p^{*}=.85$ & $p^{*}=.90$ & $p^{*}=.95$ \\
\hline$c^{*}=0$ & +.566 & +.449 & -.601 \\
\hline$c^{*}=.10$ & +.466 & +.274 & -.698 \\
\hline$c^{*}=.40$ & +.315 & +.126 & -.715 \\
\hline
\end{tabular}

All the numbers in the first and the second column of both panels (where $p^{*} \leq p$ ) are positive, and all the numbers in the third column (where $p^{*}>p$ ) are negative, which indicates that the takeover of the foreign bank by the domestic bank will take place unless the investments of the former are sufficiently safer than the investments of the latter. As stated in Proposition 3, an increase in the foreign closure cost, $c^{*}$, which proxies the size of the foreign bank in the foreign banking market, reduces the difference $\bar{V}-\left(V+V^{*}\right)$, and hence makes the takeover less likely. Finally, comparing the numbers in Panel A with those in Panel B we can see that an increase in $\lambda$ increases the difference $\bar{V}-\left(V+V^{*}\right)$ in the first two columns and decreases it in the 
third. Hence we conclude that the effect of the relative size of the two banks on the likelihood of a takeover is ambiguous.

Summing up, in this section we have shown that the takeover of the foreign bank by the domestic bank is more likely to happen if the foreign bank is small (relative to the foreign banking market) and its investments are risky (relative to those of the domestic bank), and if deposit insurance premia are lower in the domestic country. Moreover, the numerical results suggest that the relative riskiness of the two banks is the key determinant of international takeovers in banking.

\section{The Effects on Welfare}

This section discusses the welfare effects for the domestic and the foreign country of the takeover of the foreign bank by the domestic bank. Obviously, this requires to restrict attention to situations in which the domestic bank wants to buy the foreign bank (i.e. that satisfy $\bar{V}>V+V^{*}$ ).

To analyze the welfare effects for the foreign country we have to compare social welfare before and after the merger. Following our discussion in Section 2, the former is given by $W^{*}=V^{*}+U^{*}$, while the latter is $\bar{W}^{*}=P+\bar{U}^{*}$, where $P$ is the price paid by the domestic bank to the owners of the foreign bank, and $\bar{U}^{*}$ is the expected utility of the foreign supervisor after the merger. Taking into account the fact that after the merger the foreign deposit insurance corporation does not charge the deposit insurance premium $\phi^{*}$ nor she pays any compensation to depositors, it is clear from (15) that $\bar{U}^{*}=-\lambda c^{*}$.

Since $P>V^{*}$ (otherwise the owners of the foreign bank would not want to sell), a sufficient condition for the takeover to be welfare improving for the foreign country is that

$$
\bar{U}^{*}-U^{*}=\frac{\lambda\left[z_{\alpha}^{*}\left(1-L^{*}\right)+z_{1}^{*}-\phi^{*}\right]}{z_{\alpha}^{*}+z_{1}^{*}} \geq 0
$$

which is equivalent to

$$
\phi^{*} \leq z_{\alpha}^{*}\left(1-L^{*}\right)+z_{1}^{*}
$$

In other words, the foreign country will be better off if the deposit insurance premium, $\phi^{*}$, is below the expected compensation paid to depositors, $z_{\alpha}^{*}\left(1-L^{*}\right)+z_{1}^{*}$ (i.e. if before the takeover the premium was below its fair level). 
Using (12), (13), and (11) one can show that

$$
\frac{\partial\left[z_{\alpha}^{*}\left(1-L^{*}\right)+z_{1}^{*}\right]}{\partial c^{*}}=\frac{c^{*}}{1+c^{*}} \widehat{s}^{* 2} f\left(\widehat{s}^{*}\right)>0,
$$

so the expected compensation paid to depositors (per unit of deposits) would be higher for large banks. Also we expect this compensation to be higher for riskier banks. Hence we conclude that the takeover of a large and risky foreign bank will in general increase the welfare of the foreign country.

Table 3 illustrates these results for the parameterization introduced in Section 4. As before, we assume that the deposit insurance premium $\phi^{*}$ is fair for $p^{*}=.90$ and $c^{*}=.10$.

TABLE 3: Change in the expected utility of the foreign supervisor $\left(\bar{U}^{*}-U^{*}\right)$

\begin{tabular}{|c|c|c|c|}
\multicolumn{1}{c|}{} & \multicolumn{3}{c}{ Panel A: $\lambda=.10$} \\
\cline { 2 - 4 } \multicolumn{1}{c|}{} & $p^{*}=.85$ & $p^{*}=.90$ & $p^{*}=.95$ \\
\hline$c^{*}=0$ & +.012 & -.001 & -.086 \\
\hline$c^{*}=.10$ & +.016 & 0 & -.091 \\
\hline$c^{*}=.40$ & +.028 & +.003 & -.091 \\
\hline
\end{tabular}

Panel B: $\lambda=.25$

\begin{tabular}{|c|c|c|c|}
\cline { 2 - 4 } \multicolumn{1}{c|}{} & $p^{*}=.85$ & $p^{*}=.90$ & $p^{*}=.95$ \\
\hline$c^{*}=0$ & +.029 & -.002 & -.216 \\
\hline$c^{*}=.10$ & +.040 & 0 & -.227 \\
\hline$c^{*}=.40$ & +.070 & +.008 & -.228 \\
\hline
\end{tabular}

From Table 2 we know that the domestic bank will take over the foreign bank for $p^{*}=.85$ and $p^{*}=.90$, in which case the price $P$ paid by the domestic bank to the owners of the foreign bank will be greater than the market value $V^{*}$ of the foreign bank prior to the takeover. Since all the numbers in the first column of Table 3 are positive, and the numbers in the second column are either positive or, in the case of the value corresponding to $c^{*}=0$, very small compared to the corresponding value in Table 2, we conclude that the takeover increases the welfare of the foreign country. ${ }^{19}$

\footnotetext{
${ }^{19}$ This result implies that the concerns of Mayes and Vesala (1998) on the possible negative effects for the country of the target bank are not supported by our analysis.
} 
To analyze the welfare effects for the domestic country we also compare social welfare before and after the merger. Following our discussion in Section 2, the former is given by $W=V+U$, while the latter is $\bar{W}=(\bar{V}-P)+\bar{U}$, where $\bar{V}-P$ is the difference between the market value of the international bank and the price paid to the owners of the foreign bank, and $\bar{U}$ is the expected utility of the domestic supervisor after the merger. To compute $\bar{U}$, notice that the analysis in Section 3 implies that with probability $\bar{z}_{\alpha}$ the supervisor will incur a cost $1-L+\lambda\left(1-L^{*}\right)+c$, and with probability $\bar{z}_{1}$ her expected cost will be $1+\lambda\left(1-p^{*} R^{*}\right)+c$, so $\bar{U}$ satisfies the equation $\bar{U}=(1+\lambda) \phi-\bar{z}_{\alpha}\left[1-L+\lambda\left(1-L^{*}\right)+c\right]-\bar{z}_{1}\left[1+\lambda\left(1-p^{*} R^{*}\right)+c\right]+\left(1-\bar{z}_{\alpha}-\bar{z}_{1}\right) \bar{U}$.

Solving for $\bar{U}$ and rearranging then gives

$$
\bar{U}=\frac{\left[\phi-\bar{z}_{\alpha}(1-L)-\bar{z}_{1}\right]+\lambda\left[\phi-\bar{z}_{\alpha}\left(1-L^{*}\right)-\bar{z}_{1}\left(1-p^{*} R^{*}\right)\right]}{\bar{z}_{\alpha}+\bar{z}_{1}}-c .
$$

Since $\bar{V}-P>V$ (otherwise the owners of the domestic bank would not want to buy), a sufficient condition for the takeover to be welfare improving for the domestic country is that $\bar{U} \geq U$. Using (7) and (27) this will hold if

$$
\frac{\phi-\bar{z}_{\alpha}(1-L)-\bar{z}_{1}}{\bar{z}_{\alpha}+\bar{z}_{1}} \geq \frac{\phi-z_{\alpha}(1-L)-z_{1}}{z_{\alpha}+z_{1}}
$$

and

$$
\phi \geq \bar{z}_{\alpha}\left(1-L^{*}\right)+\bar{z}_{1}\left(1-p^{*} R^{*}\right)
$$

The first condition is not generally satisfied, since it is equivalent to

$$
\phi\left(\frac{1}{\bar{z}_{\alpha}+\bar{z}_{1}}-\frac{1}{z_{\alpha}+z_{1}}\right)+L\left(\frac{\bar{z}_{\alpha}}{\bar{z}_{\alpha}+\bar{z}_{1}}-\frac{z_{\alpha}}{z_{\alpha}+z_{1}}\right) \geq 0
$$

and by (23), (24) and (25) we have $\bar{z}_{\alpha}+\bar{z}_{1}<z_{\alpha}+z_{1}$ and $\bar{z}_{1} / \bar{z}_{\alpha}>z_{1} / z_{\alpha}$, so the first term is positive and the second is negative. On the other hand, since $p^{*} R^{*}>1$, the second condition will be satisfied as long as the deposit insurance premium $\phi$ is not too small. ${ }^{20}$

Given this ambiguity, we resort to a numerical illustration for the parameterization introduced in Section 4. Table 4 shows the change in the expected utility of the

\footnotetext{
${ }^{20}$ In particular, if $\phi=z_{\alpha}(1-L)+z_{1}$ (the case of fair premia) and $L=L^{*}, z_{\alpha}>\bar{z}_{\alpha}$ implies that this condition holds.
} 
domestic supervisor for $p=.90$ and $c=.10$, and for $p^{*}=.85, .90$, and .95 , and $\lambda=.10$, and $.25 .{ }^{21}$ Since all the numbers in this table are positive, we conclude that, for this set of parameter values, the takeover of the foreign bank by the domestic bank is also welfare improving for the domestic country.

TABLE 4: Change in the expected utility of the domestic supervisor $(\bar{U}-U)$

\begin{tabular}{|c|c|c|c|}
\cline { 2 - 4 } \multicolumn{1}{c|}{} & $p^{*}=.85$ & $p^{*}=.90$ & $p^{*}=.95$ \\
\hline$\lambda=.10$ & +.095 & +.101 & +.107 \\
\hline$\lambda=.25$ & +.262 & +.280 & +.298 \\
\hline
\end{tabular}

The results in this section may be a bit puzzling, since they imply that the loss of supervisory information on the foreign bank can be welfare improving. In order to explain this puzzle, it is important to recall that in our model bank supervisors do not maximize social welfare, since they do not take into consideration the utility of the bank owners. The bias in the closure policy introduced by this distorted objective function can be derived as follows. For the domestic bank, a social welfare maximizer supervisor would compare the net return, $L-c$, if the bank is closed at date $t+\alpha$, with the conditional expected return, $s R-(1-s) c$, if it is not. ${ }^{22}$ The critical value that characterizes the closure policy of this supervisor would then be

$$
\widehat{\widehat{s}}=\frac{L}{R+c} .
$$

Comparing (28) with (3) we get $\widehat{\widehat{s}}<\widehat{s}$, so the supervisor in our model is too tough, closing the bank in states where it would be optimal to keep it open. Since we have shown that the takeover of the foreign bank by the domestic bank makes the domestic supervisor softer (recall that $\bar{s}<\widehat{s}$ ), it follows that the takeover moves the critical value of the signal $s$ in the right direction, and so it can be welfare improving. Moreover, the fact that $\lim _{\lambda \rightarrow 0} \bar{s}=\widehat{s}$ implies that this will be the case unless the foreign bank is too large relative to the domestic bank. Hence we conclude that the reason why the loss of supervisory information may increase social welfare is that it serves to compensate the bias in the closure policy of the supervisory authority.

\footnotetext{
${ }^{21}$ Recall that the domestic supervisor does not take into account the foreign closure cost, so the results for the different values of $c^{*}$ are all the same.

${ }^{22}$ To simplify the discussion we consider the case of a myopic supervisor, but the argument would be essentially the same for a non-myopic supervisor.
} 


\section{Concluding Remarks}

We have developed a model of international takeovers in banking based on the risk diversification motive of mergers. The novel feature of the model is that it explicitly takes into consideration the regulatory framework that characterizes the activity of banks, in particular the existence of bank supervision and deposit insurance, and in the case of international banks the principle of home country control. The model is built on two key hypothesis. First, we assume that bank supervisors have their own objective functions that do not correspond with the maximization of social welfare. Second, we assume that the takeover implies the loss of supervisory information on the target bank.

The paper characterizes the conditions under which the takeover is more likely to occur, and analyzes its welfare effects for both countries. We show that target banks are expected to be "not too big to fail", risky banks located in countries with relatively high deposit insurance premia, and that both countries are likely to be better off as a result of the merger.

It is important, however, to bear in mind some of the limitations of our analysis. First, we restrict attention to takeovers in which the target bank becomes a branch (not a subsidiary) of the raider bank. Second, we assume that the target bank is not too large relative to the raider bank. Third, we ignore any moral hazard considerations. Overcoming these limitations constitutes an interesting topic for further research. Specifically, under what conditions the target bank will become a branch or a subsidiary of the raider bank, which bank should be the target and which the raider, or how risk-shifting incentives may affect the results.

Finally, the model can also be extended to analyze domestic bank mergers in which (i) there may be some correlation in the returns of the assets of the two banks, (ii) there is no loss of supervisory information, and (iii) the domestic supervisor also cares about the closure costs of the target bank. 


\section{References}

[1] Basle Committee on Banking Supervision (1997): Core Principles for Effective Banking Supervision.

[2] Berger, A. N., R. S. Demsetz, and P. E. Strahan (1999): "The Consolidation of the Financial Services Industry: Causes, Consequences, and Implications for the Future," Journal of Banking and Finance, 23, 135-194.

[3] Berger, A. N., R. DeYoung, H. Genay, and G. F. Udell (2000): "Globalization of Financial Institutions: Evidence from Cross-Border Banking Performance," Brookings-Wharton Papers on Financial Services, forthcoming.

[4] Davis, S. I. (2000): Bank Mergers: Lessons for the Future, New York, N.Y.: St. Martin's Press.

[5] Dermine, J. (1999): "The Economics of Bank Mergers in the European Union. A Review of the Public Policy Issues," mimeo.

[6] Dewatripont, M., and J. Tirole (1993): The Prudential Regulation of Banks, Cambridge, Mass.: MIT Press.

[7] European Central Bank (1999): Possible Effects of EMU on the EU Banking Systems in the Medium to Long Term.

[8] Hellmann, T. F., K. C. Murdock, and J. E. Stiglitz (2000): "Liberalization, Moral Hazard in Banking, and Prudential Regulation: Are Capital Requirements Enough?", American Economic Review, 90, 147-165.

[9] Keeley, M. C. (1990): "Deposit Insurance, Risk, and Market Power in Banking," American Economic Review, 80, 1183-1200.

[10] Mailath, G. J., and L. J. Mester (1994): "A Positive Analysis of Bank Closure," Journal of Financial Intermediation, 3, 272-299.

[11] Mayes, D., and J. Vesala (1998): "On the Problems of Home Country Control," Bank of Finland Discussion Paper No. 20/98. 
[12] Repullo, R. (2000): "Who Should Act as Lender of Last Resort? An Incomplete Contracts Model", Journal of Money, Credit, and Banking, 32, 580-605.

[13] Suarez, J. (1994): "Closure Rules, Market Power and Risk-Taking in a Dynamic Model of Bank Behaviour," LSE Financial Markets Group Discussion Paper No. 196. 